\title{
INSIGHTS MARXIANO-LACANIANOS E RETHELIANO-KANTIANOS NA LEITURA DAS FORMAS DO FETICHISMO DA MERCADORIA, DA IDEOLOGIA E DA EDUCAÇÃO, COM BASE EM SLAVOJ ZIZEK
}

Hildemar Luiz $\operatorname{Rech}^{1}$

\begin{abstract}
Resumo: Na perspectiva marxiana de Zizek, há, no cerne da circulação do capital, uma fantasia "objetivamente social" de reprodução autogeradora do próprio capital, que encobre a exploração dos trabalhadores e a extração da mais-valia. Ademais, segundo Zizek, para Marx, em sua análise do Livro I do Capital, a ilusão fetichista inerente a forma da mercadoria não se localiza no pensamento, mas na inter-relação prática (inconsciente) entre os homens. Ou seja, a forma mercadoria aparenta ter poderes fantasmagóricos, como se ela tivesse propriedades sociais que fossem uma determinação objetiva dos próprios produtos do trabalho enquanto mercadorias. Porém, o que os indivíduos não conhecem é a "inversão fetichista" a que obedecem em sua inter-relação prática e social. Por sua vez, Sohn-Rethel é um autor que mostrou que, além do segredo oculto do valor trabalho, a análise da forma da mercadoria também deve levar em conta a explicação histórica do modo de pensamento conceitual abstrato, combinando a estrutura do universo da mercadoria com o do espaço transcendental kantiano. Desse modo, a efetividade social do processo de troca só captura os indivíduos que dele participam enquanto estes não são cientes da lógica inerente a este processo. E esta também é a dimensão fundamental da ideologia, pois esta não funciona simplesmente como uma "falsa consciência", pois é a própria realidade social que é vivenciada de modo desapercebidamente distorcido mediante a ideologia. Já no que se refere à forma da educação, ela, nos países capitalistas, corresponde a um flagrante ataque ao uso público da razão, pois o próprio ensino está sendo crescentemente privatizado, além de estar preferencialmente a serviço da busca da produtividade, competitividade, eficiência e rentabilidade do capital.
\end{abstract}

Palavras-chave: fetichismo da mercadoria; ideologia; uso privado da razão; educação.

Abstract: Focusing on the marxian point of view of Slavoj Zizek, these author emphasizes that there is, in the core of capital circulation, an objectively social fantasy overlapped with the auto-generating reproduction of capital, which conceals workers' exploitation, and the plus-value extraction. Moreover, according Zizek, for Marx, in his analyses in the Book I of Capital, the fetishist illusion - which is inherent to the commodity form -, isn't located in the thought (or in mind), but in the practical interrelationship (which is unconscious) amongst human beings. That's to say that the commodity form gives us an appearance of having ghostly powers, like it had natural social properties, which were an objective determination of the own work's products while commodities. However, what individuals (persons) doesn't know is the "fetishist inversion" to it they obeys in their practice and social inter-relationship. On the other hand, Sohn-Rethel is an author who shows that, beyond the hidden secret of work's value, the analyses of commodity form must also take into account the historic

\footnotetext{
1 Doutor em Ciências Sociais pelo IFCH da UNICAMP, SP, com Estágio Doutoral (como Visiting Researcher) na Universidade de Manchester, Inglaterra; Pesquisador e Professor Associado IV no Depto. Fundamentos da Educação e no Programa de Pós-Graduação em Educação na FACED-UFC. E-mail: hluizrech@gmail.com
} 
explanation of the abstract conceptual thinking way, combining the structure of the commodity universe with the Kantian transcendental space. In this way, the social effectiveness of exchanging process only captures the individuals, who share in with them, while they aren't aware of the inherent logic of this process. And this also is the fundamental dimension of ideology, as it doesn't simply function as a false conscience, since it's the true social reality which is experienced in an unnoticed distorted way, through ideology. On other side, as regards to education, we can perceive that in capitalist countries, it corresponds to one flagrant attack to public use of reason, since education in that countries is growingly being privatized, so that it's preferably in tune with the service to the search in obtain increasingly high productivity, competitiveness, efficiency and profitability of capital.

Key-words: commodity fetishism; ideology; privatized use of reason; education.

Em sua análise do "segredo da forma-mercadoria” Karl Marx (2013) mostra como é importante o desencobrimento do sentido oculto por trás da forma-mercadoria, pois o valor de uma mercadoria não depende do puro acaso de uma interação acidental entre a oferta e a procura, por exemplo. Mas, o dar-se conta disto ainda é insuficiente para o desvendamento de todo o caráter fetichista da mercadoria, pois a própria economia política burguesa clássica já descobrira o segredo da forma-mercadoria. Então o verdadeiro segredo não é o segredo por trás da forma, mas o segredo da própria forma, sua gênese e a prática que cria esta forma. Ou seja, conforme Zizek (1996B, p.301), a economia política clássica nunca se perguntou: Por que o conteúdo da mercadoria assumiu tal forma particular? Isto é, por que o trabalho se expressa num valor, e por que a mensuração do trabalho por sua duração se expressa na magnitude do valor produto?”.

A análise marxista da forma-mercadoria nos acessa, de certo modo, o inconsciente desta forma, oferecendo-nos uma espécie de matriz que nos faculta gerar e captar todas as outras formas da "inversão fetichista". Ou seja, o algo a mais em jogo na forma-mercadoria, além do segredo oculto que consiste no fato de o trabalho ser a verdadeira fonte da riqueza, é o que exerce um poder de atração tão fascinante sobre gerações de filósofos, sociólogos, economistas e historiadores da arte.

A propósito, devemos aqui ressaltar que Marx extraiu elementos lógicos, metodológicos e teóricos da terminologia dialética de Hegel, para escrever os Grundrisse; mas quando elaborou o Capital já tinha se tornado claro para ele que havia uma determinada mistificação idealista na dialética hegeliana, que refletia as "sutilezas metafísicas e minúcias teológicas" que constituem o movimento secreto da mercadoria.

Nesta perspectiva, segundo Zizek (2012, p.182-83): 
A primeira coisa que devemos notar é que a leitura da dialética de Hegel como formulação idealista da lógica da dominação capitalista não vai até o fim. Desse ponto de vista, o que Hegel desenvolve é a expressão mistificada da mistificação imanente à circulação do capital ou, em termos lacanianos, de sua fantasia "objetivamente social"; em termos um tanto ingênuos [simplificados], o capital para Marx não é "realmente" uma substância-sujeito que se reproduz ao postular os próprios pressupostos e assim por diante; o que esta fantasia hegeliana de reprodução autogeradora do capital encobre é a exploração dos trabalhadores, que é como o círculo de auto-reprodução do capital tirando energia de uma fonte externa (ou melhor, "extimada") de valor, parasitando os trabalhadores. Então por que Marx não passa diretamente para a descrição da exploração dos trabalhadores, por que se preocupar com as fantasias que sustentam o funcionamento do capital? [Porque] para Marx, é fundamental incluir na descrição do capital, esse nível intermediário de "fantasia objetiva". [Pois, este nível] (...) não é nem o modo como o capitalismo é vivenciado por seus sujeitos [capitalistas] - [na medida em que], eles são bons nominalistas empíricos, sem consciência das "minúcias teológicas" do capital, e nem é o "real estado de coisas", [expresso no fato de os trabalhadores serem explorados pelo capital].

No desenrolar de sua análise, Karl Marx exprime, em seu Livro I do Capital (2013), que a ilusão fetichista não se localiza no pensamento; não se situa no modo equivocado como percebemos o que somos e fazemos, mas "em nossa inter-relação prática", ou seja, em nossa própria prática social. Ou seja, a forma-mercadoria aparenta ter em si mesma, poderes mistificadores ou fantasmagóricos, como se ela tivesse propriedades sociais que lhe pertencessem por natureza; como se estas propriedades sociais fossem uma determinação objetiva dos próprios produtos do trabalho enquanto mercadorias, que como tal são concebidos aparecendo imediatamente como intercambiáveis, parecendo existir assim também para os próprios sentidos humanos.

Segundo Zizek (2012, p.180):

É exatamente assim que devemos ler a fórmula geral de Marx a respeito da mistificação fetichista ("sie wissen das nicht, aber sie tun es", isto é, eles não conhecem, mas fazem): o que os indivíduos não conhecem é a "inversão" fetichista a que obedecem "em sua inter-relação prática", isto é, na própria realidade social. 
Nestes termos, o "fetichismo da mercadoria" exprime-se mediante a crença de que as mercadorias são objetos mágicos, dotados de poderes metafísicos inerentes. Mas ele não funciona e se sustenta por meio do pensamento em nossa mente, mas no modo como percebemos equivocadamente a realidade, em nossa própria prática social.

Nesta mesma perspectiva, cabe observar também que, segundo uma leitura marxiana não dogmática e não positivista, o trabalho é a origem do valor; mas que a troca como aparência do valor também é fundamental, pois é através dela que o valor se livra da força determinante do valor de uso. O equivalente geral dos valores de uso precisa ser privado do valor de uso. E é isto que permite ao valor ser mais-valia, além de valor de uso. Ademais, o "trabalho abstrato" é uma relação de valor que só se constitui na troca, porque não é uma propriedade substancial de uma mercadoria, independentemente de suas relações com outras mercadorias. Portanto, não é adequado conceber o valor como imanente ou inerente à mercadoria; é equivocado conceber o valor como propriedade da mercadoria, porque isto significaria, conforme Zizek (2012), naturalizar a objetividade espectral da mercadoria, que equivale apenas à aparência fetichizada de seu caráter social.

Conforme Zizek (2012, p.172), ao tratar-se deste tema não se está lidando com simples minúcias teóricas:

A determinação exata da condição do dinheiro tem consequiências
político-econômicas cruciais. [Assim] se concebermos o dinheiro
apenas como uma forma de expressão secundária do valor (...);
[ou seja, se para nós o dinheiro for apenas um simples recurso
secundário, a ponto de o considerarmos somente como um meio
prático que facilita a troca] a porta se abre para a ilusão dos
seguidores esquerdistas de Ricardo. Estes que propuseram
substituir o dinheiro por notas simples que designassem a
quantidade de trabalho feito pelo portador e lhe dessem o direito à
parte correspondente do produto social - como se por meio dessa
"moeda de trabalho" direta, pudéssemos evitar o "fetichismo" e
assegurar que cada trabalhador receba seu "valor total". O que a
análise de Marx mostra é que este projeto [dos ricardianos de
esquerda] não leva em conta as determinações formais do
dinheiro, que fazem do fetichismo um efeito necessário.

No cerne do movimento do capital, o valor não é uma mera universalidade abstrata; ele não é um vínculo substancial entre a diversidade das mercadorias (seja 
dinheiro; mercadorias materiais ou mercadorias imateriais), mas, ao contrário, conforme Zizek (2012, pp. 178-179):

De meio de troca passivo, o valor se transforma no "fator ativo" do processo como um todo. Em vez de apenas assumir passivamente as duas formas de sua existência real (dinheiromercadoria), ele aparece como o sujeito dotado de movimento próprio, passando por um processo de vida próprio. Ele se diferencia de si mesmo, postula sua alteridade e depois supera mais uma vez essa diferença; (...) o movimento é seu próprio movimento (...); em vez de simplesmente representar a relação entre mercadorias, ele entra em relação consigo mesmo. [Ou seja], a verdade de sua relação com a alteridade é auto-referente, isto é em seu movimento próprio o capital [que está empenhado na realização e apropriação do valor] "suprassume" retroativamente as próprias condições materiais e transforma-as em momentos subordinados da própria "expansão espontânea".

Ainda no que se refere à temática da mercadoria no capitalismo, o estudioso que, segundo Zizek (2012), apresentou a reflexão mais aprofundada, na revelação do alcance universal da forma-mercadoria, foi Alfred Sohn-Rethel, membro da Escola de Frankfurt. Conforme esse autor, não somente a chave da crítica da economia política - o segredo oculto do valor trabalho - integra a análise formal da mercadoria; mas também a explicação histórica do modo de pensamento conceitual abstrato e da divisão entre trabalho intelectual e manual, que passou a existir juntamente com ele.

Nas palavras de Zizek (2012, p.175), Sohn-Rethel teorizou a idéia de um paralelo entre a crítica transcendental de Immanuel Kant e a crítica da economia política de Karl Marx, mas em uma direção inversa:

A estrutura do universo da mercadoria é a do espaço transcendental kantiano. Ou seja, o objetivo de Sohn-Rethel era combinar a epistemologia kantiana com a crítica da economia política de Marx. Quando trocam mercadorias, os indivíduos abstraem o valor de uso específico - só o valor importa. Marx chamou essa abstração de "real", porque ocorre na realidade social da troca sem esforço consciente - ter ou não ter consciência dela não tem nenhuma importância. E, para Sohn-Rethel, esse tipo de abstração é a base real do pensamento formal e abstrato. Todas as categorias de Kant, como espaço, tempo, qualidade, substância, [causa e efeito], acaso, movimento e assim por diante, estão implícitas no ato da troca. Portanto há uma identidade formal entre a epistemologia burguesa e a forma social da troca, 
já que ambas envolvem uma abstração. A separação histórica entre troca e uso é que embasa a possibilidade de pensamento abstrato, tanto entre os gregos quanto nas sociedades modernas. Como origem da síntese social, a troca de mercadorias condiciona a possibilidade de todas as suas formas pensadas; a troca é abstrata e social, ao contrário da experiência privada do uso.

Sohn-Rethel (1977) amplia até a própria natureza o alcance da mediação histórico-social ensejada pela forma-mercadoria que é base do pensamento formal e abstrato moderno. Ou seja, o fetichismo da mercadoria não condiciona apenas a abstração de uma realidade específica; mas, como destaca Zizek (2012, p.176), ele condiciona: “A própria noção de natureza como 'realidade objetiva' privada de todo o significado, como domínio de fatos neutros opostos a nossos valores subjetivos". Ou seja, só numa sociedade onde predomina a forma mercadoria isto pode ocorrer. Desse modo: "O próprio surgimento das ciências naturais 'objetivas' que reduzem os fenômenos naturais a dados positivos sem significado é estritamente correlato ao surgimento da troca de mercadorias".

Como observa o próprio Sohn-Rethel (1977; pp.66-67):

Pode ser confuso ouvir que a noção de natureza como mundoobjeto físico independente do homem surge da produção de mercadorias quando esta atinge seu crescimento total como economia monetária. No entanto, essa é uma descrição verdadeira do modo como essa concepção da natureza se enraíza na história; ela aparece quando as relações sociais enquanto tais assumem o caráter impessoal e reificado de troca de mercadorias.

Nesta mesma perspectiva, também Giörgy Lukács, em sua obra "História e Consciência de Classe” (2012), ressalta com ênfase que a natureza é uma categoria social, pois o que aparenta ser natural é realmente sempre sobre-determinado e mediado por uma formação social, ou melhor, uma totalidade social historicamente específica.

O próprio Karl Marx, em sua obra "O Capital", analisa a mercadoria não somente como objeto, mas também como forma fundamental e historicamente singular das relações sociais que caracterizam a sociedade capitalista.

Conforme Moishe Postone (1995, p.153):

Marx tomou a palavra mercadoria e usou-a para designar uma forma de relação social historicamente específica, constituída 
como forma estruturada de prática social que, ao mesmo tempo, é um princípio estruturador das ações, das visões de mundo e das disposições dos indivíduos. Como categoria de prática, é uma forma tanto de subjetividade quanto de objetividade social.

Nas palavras de Zizek (1996B), a anatomia ou o esqueleto do próprio sujeito transcendental kantiano - isto é, a rede de categorias transcendentais, que constituem o arcabouço a priori do conhecimento científico “objetivo", vem articulada de antemão pela própria estrutura da forma-mercadoria. O paradoxo da forma-mercadoria, esse fenômeno patológico intramundano sob o olhar kantiano, consiste em ela fornecer-nos uma senha de acesso para solucionar a questão fundamental da teoria do conhecimento: Como é possível um conhecimento objetivo com validade universal?

A propósito, segundo Zizek ( 1996B, p.302), uma série de análises detalhadas de Sohn-Rethel levou à seguinte conclusão:

O método científico (o da ciência newtoniana da natureza) pressupõe um aparato de categorias, uma rede de noções através das quais ele capta a natureza; tal aparato já está presente na efetividade social, já está em ação no ato da troca da mercadoria. [Ou seja], antes que o pensamento pudesse chegar à pura abstração, a abstração já atuava na efetividade social do mercado. A troca de mercadorias implica uma dupla abstração: a abstração do caráter mutável da mercadoria durante o ato de troca e a abstração do caráter concreto, empírico, sensorial e particular da mercadoria. [Assim, no próprio] ato de troca, a determinação qualitativa particular e distintiva de uma mercadoria não é levada em conta; a mercadoria é reduzida a uma entidade abstrata, que independentemente de sua natureza particular, de seu "valor de uso" - tem "o mesmo valor" que outra mercadoria pela qual é trocada.

Portanto, o sine qua non da ciência moderna, expresso na quantidade pura, já estava em ação na mercadoria-dinheiro que possibilitou a comensurabilidade do valor de todas as outras mercadorias, a despeito de sua determinação qualitativa particular. E a ação deste equivalente geral que é o dinheiro já estava efetivamente presente na prática, antes que o próprio pensamento pudesse chegar à idéia de uma determinação puramente quantitativa. Desse modo, o ato social da troca, deixando totalmente intactas as propriedades sensório-concretas do objeto apanhado em movimento, já havia realizado um movimento abstrato "puro", mediante a transferência de propriedade das mercadorias. Isso ocorreu, antes que a física pudesse articular a noção de um 
movimento puramente abstrato, ocorrendo num espaço geométrico, independentemente de quaisquer determinações qualitativas dos objetos em movimento (ZIZEK, 2012).

$\mathrm{Na}$ efetividade social do mercado as moedas são tratadas como uma substância imutável, especial e sublime; uma substância em relação à qual o tempo não exerce nenhum poder e que se situa num contraste antitético com qualquer material encontrado na natureza. A propósito, conforme Zizek (1996B, pp.302-3):

O sujeito transcendental, esteio da rede de categorias a priori, confronta-se com o fato inquietante de que depende, em sua própria gênese formal, de um processo "patológico" intramundano. [Isto, porém, representa] um escândalo, uma impossibilidade absurda do ponto de vista transcendental, na medida em que o a priori formal-transcendental é, por definição, independente de todos os conteúdos positivos. [Em outras palavras, este é] um escândalo perfeitamente correspondente ao caráter escandaloso do inconsciente freudiano, que também é intolerável do ponto de vista transcendental-filosófico. Ou seja, se examinarmos de perto o status ontológico, do que Sohn-Rethel chama de "abstração real" [isto é, o ato de abstração que opera no próprio processo efetivo da troca de mercadorias], verificaremos ser impressionante a homologia entre seu status e o do inconsciente; dessa cadeia significante que persiste numa "outra Cena": a "abstração real" é o inconsciente do sujeito transcendental, o suporte do conhecimento científico objetivouniversal.

Sob este prisma, o problema de qual é o caráter material sui generis do dinheiro não foi integralmente solucionado por Karl Marx. Aqui evidentemente não se trata da matéria empírica de que o dinheiro é feito, mas do material sublime, daquele outro corpo intocável e não degradável que persiste para além do corpo físico. Zizek (1996B, pp.303-304) observa o seguinte a este respeito:

Esse outro corpo do dinheiro é como o cadáver da vítima sádica, que suporta todas as torturas e sobrevive com sua beleza imaculada. Essa corporalidade imaterial [etéria] do 'corpo dentro do corpo' dá-nos uma definição precisa do objeto sublime, e é somente nesse sentido que a idéia psicanalítica do dinheiro como um objeto 'pré-fálico', 'anal' [excremental], é aceitável. [Ou seja,] desde que não nos esqueçamos de como essa existência postulada do corpo sublime depende da ordem simbólica [da injunção do grande Outro]. 
Na perspectiva sohn-retheliana, a injunção de que a moeda deve servir como meio de troca e não como objeto de uso está estampado no corpo da própria moeda. E a autoridade emitente assegura a reposição plena do peso e da pureza metálica da moeda quando esta é atingida pelo desgaste da circulação. Ou seja: "Sua matéria física tornouse, visivelmente, mera portadora de sua função social” (ZIZEK, 1996B, p.304).

Sob este prisma, a abstração da troca não tem nada a ver com as propriedades efetivas de um objeto e, como tal, não se trata de uma "abstração do pensamento" que ocorre no interior do sujeito pensante. A abstração pertinente ao ato de troca é irredutivelmente exterior e descentrada. Conforme o enfoque sohn-retheliano: "A abstração da troca não é o pensamento, mas tem a forma do pensamento" (ZIZEK, 1996B, p.304).

A forma de pensamento apresenta um status ontológico que não é o do pensamento porque é externa a ele, constituída por uma “Outra Cena”, mediante a qual a forma já é externamente articulada de antemão. E essa forma anterior e externa ao pensamento, é, em suma, a ordem simbólica, que precisamente é “(...) uma ordem formal desse tipo que suplementa e/ou rompe a relação dual da realidade factual externa com a experiência interna" (ZIZEK, 1996B, p.304).

Portanto, a abstração da troca não pode ser concebida como um processo que ocorre no campo do conhecimento por que a forma de pensamento que envolve a abstração é anterior e externa ao pensamento, integrando a ordem simbólica.

A relação entre a efetividade social da troca de mercadorias e a consciência dela, envolve um paradoxo crucial que consiste no seguinte: o não-conhecimento da realidade é parte da própria essência dessa relação. Ou seja, se viéssemos a 'saber demais', a ponto de ficarmos totalmente cientes do verdadeiro funcionamento da realidade social, essa realidade se dissolveria. “A efetividade social do processo de troca (...) só é possível (...) [se] os indivíduos que dela participam não estiverem cientes de sua lógica própria; ou seja, é um tipo de realidade cuja própria consistência ontológica implica um certo não-conhecimento de seus participantes” (ZIZEK, 1996B, p.305).

Essa, provavelmente, é a dimensão fundamental da 'ideologia', pois a ideologia não é simplesmente uma 'falsa consciência', uma representação ilusória da realidade; antes, é essa mesma realidade que já deve ser concebida como 'ideológica'.

Segundo Zizek (1996B, p.305-6): 
"Ideológica" é uma realidade social cuja própria existência implica o não-conhecimento dos participantes, ou seja, a efetividade social cuja própria reprodução implica que os indivíduos "não sabem o que fazem". "Ideológica" não é a "falsa consciência" de um ser (social), mas esse próprio ser, na medida em que ele é sustentado pela 'falsa consciência'.

De modo semelhante, outra formação, cuja consistência e funcionamento implica um não-conhecimento por parte do sujeito, é a dimensão do sintoma. Ou seja, o sujeito somente pode gozar com o sintoma na medida em que a sua lógica lhe escapa. Tendo em conta isto, Zizek (1996B) então se pergunta de como podemos definir o sintoma marxista?

A partir de uma perspectiva lacaniana, Marx "inventou o sintoma" mediante a identificação de uma fissura, de uma assimetria, de um desequilíbrio patológico que desmente o universalismo dos "direitos e deveres burgueses".

Longe de estabelecer o anúncio de uma realização parcial e ainda inacabada dos direitos e deveres universais, esse desequilíbrio funciona como o próprio momento constitutivo desse universalismo. Ou seja, o sintoma, no sentido estrito, é um mecanismo particular que subverte seu próprio fundamento universal. Como argumenta Zizek (1996B, p.306), a este respeito:

Esse processo implica, pois, uma lógica da exceção: todo Universal ideológico - por exemplo, a liberdade, a igualdade, [a solidariedade] - é "falso", na medida em que necessariamente inclui um caso específico que rompe sua unidade, que expõe sua falsidade. A liberdade, por exemplo: é uma noção universal que abrange várias espécies (liberdade de fala e de imprensa, de consciência, de comércio, [civil] política, etc.), mas também, por uma necessidade estrutural, uma liberdade específica (a de o trabalhador vender livremente sua força de trabalho no mercado), que subverte essa noção universal. Ou seja, essa liberdade é o próprio oposto da liberdade efetiva: ao vender "livremente" sua força de trabalho, o trabalhador perde sua liberdade - o conteúdo real desse livre ato de venda é a escravização do trabalhador ao capital. $\mathrm{O}$ aspecto crucial é que essa liberdade paradoxal, a forma de seu oposto, é precisamente o que fecha o círculo das "liberdades burguesas".

O ideal do mercado capitalista que é a chamada "troca de equivalentes", apresenta uma lógica de exceção semelhante. A propósito, tão logo que prevalece a produção para o mercado na sociedade, emerge de modo disseminado um novo tipo de 
mercadoria que é a força de trabalho, como resultado da necessidade dos trabalhadores de a venderem no mercado para a sua própria sobrevivência.

Entretanto, com essa nova mercadoria a troca de equivalentes torna-se uma negação, por que a força de trabalho apresenta uma peculiaridade oculta, cujo uso produz a "mais-valia", um excedente que ultrapassa o valor contratado da força de trabalho e é apropriado pelos capitalistas. Dentro desta linha de argumentação, Zizek (1996B, p.307) observa o seguinte:

Aqui temos, mais uma vez, um certo Universal ideológico (o da troca eqüitativa de equivalentes) e uma troca paradoxal particular (a da forca de trabalho por seus salários) que, precisamente como um equivalente, funciona como a própria forma de exploração. $\mathrm{O}$ desenvolvimento "quantitativo" em si, a universalização da produção de mercadorias, promove uma nova "qualidade", a emergência de uma nova mercadoria que representa a negação interna do princípio universal da troca equivalente de mercadorias: em outras palavras, ela acarreta um sintoma (...), [o ponto de exceção que funciona como negação interna do princípio universal da troca equivalente de mercadorias].

Aliás, é com base neste paradoxo que Marx, segundo Zizek (1996B), tece uma acerbada crítica à noção hegeliana da sociedade como uma totalidade racional. Ou seja, Marx aponta o proletariado como o ponto em que a Razão incorporada na sociedade moderna vigente nutre a sua desrazão.

Ainda no que se refere ao "fetichismo da mercadoria" cabe observar que apenas em uma primeira aproximação ele é "uma relação social definida entre os homens, que assume aos olhos deles a forma fantasiosa de uma relação entre coisas”. Em seu funcionamento efetivo, o valor das mercadorias é uma insígnia de uma rede de relações sociais que assume uma propriedade quase "natural" de outra coisa-mercadoria que é o dinheiro. Desse modo, o aspecto central do "fetichismo da mercadoria" não consiste em uma relação fantasiosa de coisas, mas antes, numa determinada inconsciência (desconhecimento) da relação entre um elemento particular e uma rede estruturada de elementos da qual ele é seu elemento paradoxal de articulação. "Aquilo que é realmente um efeito estrutural, um efeito da rede de relações entre os elementos, aparece como uma propriedade imediata de um dos elementos, como se essa propriedade também lhe pertencesse fora de sua relação com os outros elementos" (ZIZEK, 1996B, p.308). 
Ademais, em sua argumentação sobre o "fetichismo da mercadoria", Marx observa uma homologia entre uma mercadoria A e outra mercadoria B, sendo esta última somente um equivalente na medida em que A se relaciona com B "como sendo a "forma da aparência" de seu próprio valor, somente dentro dessa relação. A propósito, Zizek (1996B, p.309) emenda a seguinte observação, nesta linha marxiana de argumentação:

Mas a aparência - e nisso consiste o efeito de inversão que é característica do fetichismo -, a aparência é exatamente oposta: A parece relacionar-se com $\mathrm{B}$ como se, para $\mathrm{B}$, ser um equivalente de A não correspondesse a ser uma "determinação reflexiva" (Marx) de A - ou seja, como se B já fosse, em si mesmo, equivalente a A; a propriedade de ser "equivalente" parece pertencer-lhe até mesmo fora de sua relação com A, no mesmo nível de suas outras propriedades efetivas "naturais" que constituem seu valor de uso. [A propósito, outro exemplo de Marx, que serve de ilustração para esta argumentação, é o fato de alguém "Ser rei", ou seja,] "Ser rei" é um efeito da rede de relações sociais entre um "rei" e seus "súditos"; mas - e aí está o desconhecimento fetichista -, para os participantes desse vínculo social, a relação aparece necessariamente de forma inversa: eles acham que são súditos, dando ao rei um tratamento real, porque o rei já é [visto como] rei em si mesmo, fora da relação com seus súditos; como se a determinação "ser rei" fosse uma propriedade "natural" da pessoa de um rei.

A teoria lacaniana do estádio do espelho apresenta uma forma de elaboração semelhante. Somente na medida em que outro ser humano oferece a imagem de unidade ao eu (moi), ou seja, somente quando o eu se refletir num outro é que ele pode chegar à sua auto-identidade. De modo que, de acordo com Lacan, a identidade e a alienação são estritamente correlatas.

Por outro lado, na análise do pensamento de Marx, cabe estabelecer uma ponderação bem clara sobre a sua descoberta da dimensão do sintoma. A relação Senhor e Escravo, dominante no contexto das relações servis de dominação, passou por um determinado tipo de deslocamento no capitalismo. A desfetichização das relações entre os homens ocorreu como se sua efetivação devesse que ser paga com o fetichismo nas "relações entre as coisas". Desse modo, desapareceu a transparência imediata das relações sociais mais cruciais, as de produção. Assim, o lugar do fetichismo apenas se desloca das relações intersubjetivas e interpessoais para as relações entre mercadorias, enfim entre os produtos do trabalho. Então, é na maneira como Marx abordou a 
passagem do feudalismo para o capitalismo que ocorre a descoberta do sintoma. A propósito como argumenta Zizek (1996B, p.310):

Com o estabelecimento da sociedade burguesa, as relações de dominação e servidão são recalcadas: formalmente, parecemos estar lidando apenas com sujeitos livres, cujas relações interpessoais estão isentas de qualquer fetichismo; a verdade recalcada - a da persistência da dominação e da servidão emerge num sintoma que subverte a aparência ideológica de igualdade, liberdade e assim por diante. Esse sintoma, o ponto de emergência da verdade sobre as relações sociais, são precisamente as "relações sociais entre as coisas": "Em vez de aparecer em quaisquer circunstâncias como suas próprias relações [intersubjetivas], as relações sociais entre os indivíduos disfarçam-se sob a forma de relações sociais entre as coisas" - aí temos uma definição precisa do sintoma histérico, da "histeria de conversão" que é própria do capitalismo.

De outro lado, segundo Zizek (1996A), cabe observar que Karl Marx concebeu a ideologia como uma máquina radicalmente não espontânea, que distorce de fora para dentro a autenticidade da nossa experiência de vida. Ou seja, sob este prisma, a ideologia somente surge quando as idéias distorcidas perdem seu caráter imediato e são sofisticadamente elaboradas por "intelectuais orgânicos" a fim de servir de legitimação das relações de dominação e de exploração existentes. Nesta perspectiva, a ideologia propriamente dita só surge com a divisão do trabalho, a cisão das classes sociais e o estado moderno. Por isso que Marx recusou-se a considerar o 'fetichismo da mercadoria' como uma ideologia, pois para ele esta está sempre relacionada ao Estado, sendo este considerado a primeira força ideológica. Portanto, de acordo com Marx, a ideologia não brota da "vida em si", mas só passa a existir na medida em que a sociedade é regulada por um Estado, atrelado ao processo de exploração e dominação das relações sociais capitalistas.

Para Marx, contudo, o "fetichismo da mercadoria" - este elemento idolátrico falso, esta fantasia teológica, este "elemento espectral obsceno", enfim, este universo "sui generis" da mercadoria, que acompanha a matéria espiritualizada da mercadoria, proporciona o suplemento fetichista necessário à doutrina oficial. Enfim, nestes termos, a base real deste fetichismo é a idolatria do Bezerro de ouro, o dinheiro, entronizado ilusoriamente como tendo propriedades especiais e sublimes, independentes das 
relações sociais de força e poder, enfim, das relações de exploração e de dominação na sociedade (ZIZEK, 1996A).

Sob este prisma, contudo, impõe-se uma diferença crucial entre o marxismo e a abordagem lacaniana. Ou seja:

Na perspectiva marxista predominante, o olhar ideológico é um olhar parcial, que deixa escapar a totalidade das relações sociais, ao passo que, na perspectiva lacaniana, a ideologia designa, antes, a totalidade empenhada em apagar os vestígios de sua própria impossibilidade. Essa diferença corresponde à que distingue as noções de fetichismo em Freud e em Marx: no marxismo, o fetiche oculta a rede positiva de relações sociais, ao passo que, em Freud, o fetiche oculta a falta (a "castração") em torno da qual se articula a rede simbólica (ZIZEK, 1996B, p.327).

Portanto, a partir de sua perspectiva analítica, o marxismo não consegue chegar a uma concordância com o "objeto-a-mais", com esse excesso, com esse resto do Real lacaniano que foge à simbolização; e que se articula com uma dinâmica pulsional repetitiva (wiederholungszwang), a qual funciona ao modo de insistências que se repetem frente a experiências sempre fracassadas.

Sob este ângulo, esse resto espectral do registro do Real que retorna como repetição circular repetitiva está na base da dinâmica pulsional - podendo inclusive apresentar propensões voltadas à ruptura com a rede simbólica petrificada e alienante direcionada não apenas ao "mais gozar", mas também a novas irrupções de liberdade e subjetivação. Este ponto de desencontro da perspectiva marxista com a lacaniana é surpreendente se lembrarmos que Lacan estabeleceu a noção de "mais gozar", com base na idéia marxista de mais-valia:

A prova de que a mais-valia de Marx anuncia a lógica do "objeto pequeno a" lacaniano, como encarnação do "mais-gozar", já é fornecida pela fórmula decisiva que Marx utilizou, no terceiro volume de $O$ Capital, para designar o limite lógico-histórico do capitalismo: "o limite do capital é o próprio capital, isto é, o modo de produção capitalista” (ZIZEK, 1996B, p.328).

Ou seja, o limite do capital é o seu antagonismo interno insuperável, que corresponde ao núcleo traumático do Real, instalado em sua estruturação interna.

Ainda no que se refere à abordagem de Marx sobre a dinâmica do "Capital", cabe observar que para ele a subsunção formal, do processo de produção, ao Capital

\begin{tabular}{|l|l|l|l|l|}
\hline Rovista Qialectus & Ano 3 & n. 9 & Setembro - Dezembro 2016 & p. 62 - 80 \\
\hline
\end{tabular}


precede à subsunção real. Desse modo, primeiro o capital subordina o processo de produção pré-capitalista artesanal; e somente posteriormente ele vai moldando gradativamente as forças produtivas para, na medida do possível, corresponderem à sua lógica de funcionamento e desenvolvimento, embora jamais seja possível falar de concordância e harmonia entre o desenvolvimento das forças produtivas e das relações sociais de produção no capitalismo. Assim, a contrapelo da idéia evolucionista simplista do desenvolvimento das forças produtivas, é a forma da relação de produção que impulsiona o desenvolvimento do conteúdo das forças produtivas. Como destaca Zizek (1996B, p.329):

No capitalismo, essa contradição, a discordância entre forças produtivas/relações de produção, está contida em seu próprio conceito (na forma da contradição entre o modo de produção social e o modo de apropriação privado individual). É essa contradição interna que obriga o capitalismo a uma permanente reprodução ampliada - ao desenvolvimento incessante de suas próprias condições de produção, em contraste com os modos de produção anteriores, onde, em seu estado "normal", a reprodução se dá como um movimento circular.

O próprio limite imanente do capitalismo - sua contradição interna insuperável longe de ser restritivo, impulsiona o capitalismo a um desenvolvimento permanente. $\mathrm{Ou}$ seja, conforme Zizek (1996B), desde o início o capitalismo luta contra a sua falta permanente de equilíbrio interno, contra a força fragmentadora de sua contradição mutiladora, contra seu núcleo de discórdia e de conflito. Mas luta apenas para tamponar o buraco que se reproduz incessantemente em torno do seu antagonismo traumático oculto, sem que ele jamais se disponha a desarticular esta contradição terrível. Assim, o desenvolvimento e as transformações incessantes são a única maneira de entrar em acordo, sempre de modo provisório, com seu desequilíbrio fundamental e com a sua contradição constitutiva. É desse modo, que o paradoxo característico do capitalismo, seu recurso último, consiste em ele ser capaz de transformar seu limite, a fonte de sua impotência, na fonte de seu poder. Ou seja, ele precisa revolucionar-se constantemente para poder sobreviver.

A título de conclusão: breves apontamentos sobre a pós-política contemporânea e sobre a educação 
Um dos maiores paradoxos do capitalismo global contemporâneo é a forma como ele aborda o conhecimento coletivo. Ou seja, simultaneamente que ele diminui o trabalho socialmente necessário, ele projeta todo o conhecimento e pesquisa científica e tecnológica e todo o conhecimento em geral para aumentar a centralização do capital e a concentração mundial da riqueza. Esta última fica nas mãos de minorias sociais privilegiadas, de grandes bancos, fundos de investimento e corporações econômicas, em detrimento da ampla maioria. Ou seja, ocorre hoje um aumento da composição orgânica do capital, que resulta no decréscimo do trabalho vivo, enfim, no encolhimento dos postos de trabalho, que se afigura, portanto, como um evento ou uma tendência socialmente predatória, na medida em que torna um crescente número de trabalhadores dispensáveis e inúteis.

A propósito, como destaca Zizek (2012), o resultado disso tudo é a transformação de uma significativa parte do lucro gerado pela exploração do trabalho em renda apropriada por grupos sociais privilegiados e por corporações capitalistas, mediante a privatização do conhecimento intelectual. Marx chamou este conhecimento de Intelecto Geral, o qual ele acreditava que seria socializado, de modo a estar convencido de que o processo econômico e tecnológico - enfeixado nesta ordem dinâmica - contribuiria decisivamente para a superação do capitalismo. Mas, ao contrário do que pensava Marx, o conhecimento científico e intelectual está hoje totalmente privatizado. Tanto as atividades tecnológico-científicas de pesquisa, quanto o conhecimento e seu desenvolvimento em nível global, até mesmo nas universidades públicas, estão hoje a serviço da busca de produtividade, competitividade, eficiência e rentabilidade do capital (Zizek, 2012).

As reformas mais recentes do ensino médio e superior nos países capitalistas em geral correspondem a um flagrante ataque ao uso público da razão. O próprio ensino passa a ser crescentemente privatizado. Segundo Zizek (2012, p.298): “A redução do ensino superior à tarefa de produzir conhecimento especializado socialmente útil ao capital [e ao mercado em geral] é a forma paradigmática do uso privado da razão no capitalismo global contemporâneo".

Portanto, impõe-se de modo acachapante uma privatização direta do conhecimento que exclui a reflexão sobre a forma que os problemas resultantes da crise global adquirem para aqueles homens comuns e trabalhadores que estão na base da sociedade.

Sob este prisma, a própria educação é cada vez mais uma rede que não está voltada para a promoção da cidadania, mas para as relações de mercado, ou seja, para a esfera

\begin{tabular}{|c|c|c|c|}
\hline Revista Dialectus & Ano 3 & n. 9 & Setembro - Dezembro 2016 \\
\hline
\end{tabular}


dos interesses egoístas dos agentes de mercado e do capital. Ademais, sob este aspecto, os valores iluministas de liberdade, fraternidade, igualdade e solidariedade se encontram totalmente esvaziados. E, em nome do menor custo e da maior eficiência e produtividade, o sistema educacional vem sendo crescentemente inserido em um regime de parcerias público-privadas, sob o comando dos interesses do capital.

Ademais, na esfera política contemporânea prolifera um modo pós-político e biopolítico de gestão e controle social das populações localizadas na ampla base da sociedade. Nas palavras de Zizek (2014, p.45):

A pós-política é uma política que afirma deixar para trás os velhos combates ideológicos para se centrar, por outro lado, na gestão e na administração especializadas, enquanto a biopolítica designa como seu objetivo principal a regulação da segurança e do "bem-estar" das vidas humanas [em circunstâncias econômicas restritivas]. É evidente que hoje as duas dimensões se sobrepõem: quando se renuncia às grandes causas ideológicas, tudo o que resta é a administração eficaz da vida (...), ou quase apenas isso. $O$ que significa que, com a administração especializada, despolitizada e socialmente objetiva e com a coordenação dos interesses como nível zero da política, a única maneira de introduzir paixão nesse campo e de mobilizar ativamente as pessoas é através do medo, um elemento constituinte fundamental da subjetividade de hoje.

A pós-política contemporânea, portanto, abre mão de um conjunto de axiomas universais, exprimindo-se como uma política que renuncia à própria dimensão constitutiva do político. Este modelo esvaziado de política revela o medo como seu princípio de mobilização, assentando-se na manipulação de uma multidão paranóica formada por pessoas inseguras, ameaçadas pelo risco de marginalização social e, portanto, incertas quanto ao seu destino.

Por outro lado, no que se refere ao campo da educação, cabe observar que são postos em funcionamento dispositivos de controle e de captura sobre professores e estudantes.

$\mathrm{Na}$ vida cotidiana de estudantes e professores operam idéias particulares e crenças específicas que implicam no modo como eles vêem as coisas e de como as vêem; ou seja, elas os fazem ver a realidade de modo ideologicamente distorcido.

Portanto, no campo educacional também as pessoas se interconectam e relacionam uns com os outros, impactados por posições, perspectivas e enlaçamentos que carregam a marca das coordenadas sistêmicas dominantes. Assim, por exemplo, no amoldamento contemporâneo da sociedade capitalista global, a própria educação está entrelaçada e 
capturada pela lógica competitiva e produtivista do modelo econômico; pelo fetichismo da tecnologia; pelo consumismo como modo de vida; pelas práticas flexíveis, fragmentadoras e de precarização das relações de trabalho; e, enfim pelo utilitarismo e pragmatismo econômico, que contamina a própria prática educacional.

Neste cenário são ativadas expectativas particulares, pautadas na relação clientefornecedor (provedor) no cerne do campo educacional. Ainda associado a isto, ocorre um processo intenso de privatização do ensino, em que a clientela se torna o centro da atenção em diferentes níveis, desde a escola fundamental até a educação superior.

Nestas circunstâncias, as idéias mestras, as fantasias e as crenças inconscientes que moldam e modulam o comportamento das pessoas em nível do seu cotidiano acabam por ser bem sucedidas; quando nós nem percebemos e nem nos damos conta de suas modelagens ideológicas ou de suas formas particulares de distorção que são vivenciadas como se fossem naturais e inexoráveis.

Mas, há aqueles que são bem esclarecidos sobre o caráter distorcido e corrompido das práticas de gestão da educação, mas mesmo assim cinicamente eles consentem com estas práticas corruptas e corruptoras de dominação vigentes no campo educacional; fazendo de conta que nada de grave está acontecendo, de modo que legitimam o "status quo", mesmo que no cerne das práticas vigentes explodam violências subjetivas, simbólicas e sistêmicas, inclusive no campo educacional.

Portanto, é graças aos impactos ideológicos, colados aos mecanismos ou dispositivos de dominação, que se impõem dificuldades que bloqueiam terrivelmente qualquer processo de transformação social expressivo. Isto nos ajuda a entender porque é tão desafiante e mesmo traumático implantar uma mudança radical efetivamente profunda em todo e qualquer esfera social, inclusive a educacional.

Assim, por exemplo, no plano educacional, tanto nas práticas específicas de ensino nas salas de aula, quanto em termos do modelo mais amplo - que marca o conjunto das políticas, dos programas, dos planos gerais e dos métodos de avaliação e currículo em nível nacional - ocorrem tremendas dificuldades que travam efetivas mudanças.

Nesta perspectiva, não basta que sejam estabelecidas emendas superficiais e inócuas nos currículos nacionais, estaduais e municipais de ensino, para que a educação contribua para uma perspectiva social e cultural de emancipação individual e social.

Mas, as práticas de dominação com suas ideologias sempre apresentam contradições e furos que estimulam o surgimento de práticas de resistência e de contraposição crítica que podem conduzir a movimentos de transformação efetiva. $\mathrm{Ou}$ 
seja, permanece sempre uma abertura inclusive nas relações políticas de dominação que podem resultar em transformações sociais profundas, embora a crescente complexidade das relações sociais, culturais e educacionais e os dispositivos de controle que sobre elas são postos em funcionamento aumentem as dificuldades para atos políticos de transformação profunda.

\section{Bibliografia}

LUKÁCS, Giörgy. História e Consciência de Classe. $2^{\mathrm{a}}$ ed., SP, Martins Fontes, 2012.

MARX, Karl. O capital (Crítica da economia política). Livro I: O processo de produção do capital. São Paulo, Boitempo, 2013.

POSTONE, Moishe. Rethinking Marx in a Post-Marxist World. Charles Camic (ed.); Reclaiming the Sociological Classics_- The University of Chicago, 1995.

SOHN-RETHEL, Alfred. Intelellectual and Manual Labour: A Critique of Epistemology. Atlantic Highlands, Humanities Press, 1977.

ZIZEK, Slavoj. Violência. SP, Boitempo, 2014.

. Vivendo no Final dos Tempos. São Paulo, Boitempo, 2012.

"Introdução: O espectro da ideologia". In: Theodor Adorno [et. al.], ZIZEK, Slavoj (org.). Um Mapa da Ideologia, RJ, Contraponto, 1996A, pp.7-38.

. “Como Marx inventou o sintoma?". In: Theodor Adorno [et. al.], ZIZEK,

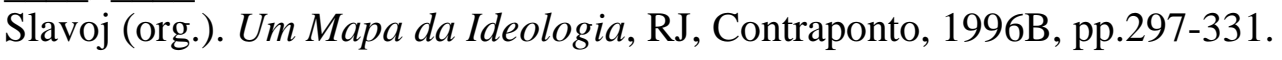

\begin{tabular}{|l|l|l|l|l|}
\hline Qevista Dialectus & Ano 3 & n. 9 & Setembro - Dezembro 2016 & p. 62 - 80
\end{tabular} 